https://helda.helsinki.fi

\title{
Hypertension and diabetes as predictors of early death after spontaneous intracerebral hemorrhage
}

\section{Tetri, Sami}

2009

Tetri , S , Juvela , S , Saloheimo , P , Pyhtinen , J \& Hillbom , M 2009 , ' Hypertension and diabetes as predictors of early death after spontaneous intracerebral hemorrhage ' , Journal of Neurosurgery , vol. 110 , no. 3 , pp. 411-417 . https://doi.org/10.3171/2008.8.JNS08445

http://hdl.handle.net/10138/224472

https://doi.org/10.3171/2008.8.JNS08445

publishedVersion

Downloaded from Helda, University of Helsinki institutional repository.

This is an electronic reprint of the original article.

This reprint may differ from the original in pagination and typographic detail.

Please cite the original version. 


\title{
Hypertension and diabetes as predictors of early death after spontaneous intracerebral hemorrhage
}

\author{
Clinical article
}

\author{
Sami Tetri, M.D., ${ }^{1}$ Seppo Juvela, M.D., Ph.D., ${ }^{4}$ Pertti Saloheimo, M.D., Ph.D., ${ }^{2}$ \\ Juhani Pyhtinen, M.D., Ph.D., ${ }^{3}$ And Matti Hillbom, M.D., Ph.D. ${ }^{2}$ \\ Departments of ${ }^{1}$ Neurosurgery, ${ }^{2}$ Neurology, and ${ }^{3}$ Radiology, Oulu University Hospital, Finland; \\ and ${ }^{4}$ Departments of Neurosurgery, Helsinki and Turku University Hospitals, Finland
}

\begin{abstract}
Object. Previous investigators have suggested that a high mean arterial blood pressure (MABP) and an elevated plasma glucose level at admission are associated with a poor outcome after hemorrhagic stroke. It remains unclear, however, whether hypertension and diabetes are responsible for this effect. High admission MABP and plasma glucose levels may also be markers of other factors such as stroke severity.

Methods. The authors retrospectively investigated the role of a high admission MABP and plasma glucose level together with other predictors of early death among 379 nonsurgical patients with spontaneous intracerebral hemorrhages (ICHs) who were admitted to the stroke unit of Oulu University Hospital.

Results. The 3 -month mortality rate was $28 \%$. The patients who died within 3 months of ICH had significantly higher plasma glucose levels and MABPs at admission $(\mathrm{p}<0.001)$. After adjustments for patient sex, age, size and location of hematoma, Glasgow Coma Scale score at admission, presence of intraventricular hemorrhage, history of cardiac disease, and previous use of warfarin, history of diabetes (relative risk 1.61, 95\% CI 1.03-2.53, p < 0.05) and high MABP at admission (relative risk 1.01 per $\mathrm{mm} \mathrm{Hg}, 95 \%$ CI 1.00-1.02, p < 0.05 ) remained independent predictors of death 3 months after ICH. A high admission plasma glucose level and history of hypertension were not independent predictors of death.

Conclusions. A high MABP at admission was found to be an independent predictor of early death in patients with ICH. History of hypertension was not responsible for the effect. Admission hyperglycemia appeared to be a stress response to the severity of the bleeding, whereas diabetes predicted early death. (DOI: $10.3171 / 2008.8$.JNSO8445)
\end{abstract}

\section{Key Words • cerebral hemorrhage • diabetes • hypertension • outcome}

$\mathrm{S}$ PONTANEOUS ICH is a devastating disease with high mortality and morbidity rates. The annual incidence of ICH varies from 10 to 20 cases per 100,000 people and increases with age. ${ }^{24}$ Recently, many new clinical factors affecting the case fatality of ICH have been identified. ${ }^{26}$ Two potential risk factors that might influence short-term outcome are admission hyperglycemia and high blood pressure at admission, which are controllable by efficient treatments. Although recent published treatment guidelines $\mathrm{s}^{3,16}$ recommend correction of hyperglycemia (Class IIa, level of evidence C) $)^{3}$ and lowering of high blood pressure (Class IIb, level of evidence $\mathrm{C})^{3}$ in the acute phase after ICH, the impact of such treatments on outcome are not yet known.

\footnotetext{
Abbreviations used in this paper: GCS = Glasgow Coma Scale; $\mathrm{ICH}=$ intracerebral hemorrhage; ICP = intracranial pressure; IVH = intraventricular hematoma; MABP = mean arterial blood pressure; $\mathrm{RR}=$ relative risk.
}

The role of high blood pressure at admission has been studied in selected patient populations with a history of hypertension and supratentorial-but not infratentorial-hemorrhage. ${ }^{79}$ The authors of these studies have reported impaired outcome after ICH in patients with a high MABP at admission. However, the confounding roles of age, stroke severity, and location have not been thoroughly investigated. Likewise, the role of admission hyperglycemia in patients with ICH has been poorly investigated, and the results are conflicting. In their review, Capes et al. ${ }^{5}$ reported no association between admission hyperglycemia and the 1-month death rate in 4 studies, whereas the authors of 2 recent studies found admission hyperglycemia to be associated with poor outcome in both diabetic and nondiabetic patients..$^{10,21}$ The authors of 2 studies reported diabetes to be an independent predictor of early death in patients with ICH. ${ }^{1,21}$

The aim of the present study was to estimate the impact of hypertension and diabetes as well as admission MABP and hyperglycemia on short-term survival in pa- 
tients with spontaneous ICH. We analyzed the effects of several factors on survival to discover which independent predictors were truly relevant and which reflected only a stress response to the severity of bleeding.

\section{Methods}

\section{Patient Population}

All patients with spontaneous ICH who were admitted to the Stroke Unit of the Department of Neurology, Oulu University Hospital, Finland, between January 1993 and January 2004 were included in this study. Our institution is the only hospital that serves patients with acute stroke in Northern Ostrobothnia (population 373,868 as of December 31, 2003). We excluded patients who were not residents in the hospital's catchment area, those with bleeding caused by brain tumors, aneurysms, vascular malformations, hematological malignancies, coagulation disorders, or head traumas, and those in need of immediate surgery. Altogether 453 patients with ICH were admitted during the study period. Most patients (94.2\%) were admitted within 48 hours of the first symptoms of ICH. Admission plasma glucose values and blood pressure levels were available in 379 patients; 74 patients who lacked this information were excluded from the study. In addition, 89 patients who required immediate surgery were also excluded. The ethics committee of our institution approved the study protocol.

\section{Neuroradiological Methods}

Intracerebral hemorrhage was verified on CT scans in all cases, and secondary structural abnormalities were sought on follow-up images (CT or MR imaging) obtained 2-3 months after the hemorrhage. Angiography was performed if aneurysmal bleeding was suspected. All CT scans were examined and the locations and volumes of hematomas measured by an experienced neuroradiologist (J.P.) blinded to the patients' case histories. The hematomas were divided into categories based on location. Hematoma volumes were measured on a workstation using the method previously described, ${ }^{2}$ and the presence of IVH was recorded.

\section{Medical Records}

Data were collected retrospectively from patient medical records. The following information was collected: time of ICH onset (as defined by acute onset of headache or neurological deficit), previous diseases, medications, and health habits such as current cigarette smoking status and recent heavy drinking. Admission plasma glucose levels and blood pressure values were obtained during transportation to the hospital or in the emergency department. Patients were considered hypertensive if their blood pressure readings prior to ICH had exceeded $160 / 90 \mathrm{~mm}$ $\mathrm{Hg}$ at least twice (in accordance with the World Health Organization/International Society of Hypertension statement) ${ }^{28}$ or if they were taking antihypertensive medication. Patients not taking antihypertensive medication but with repeated blood pressure measurements exceeding 160/90 $\mathrm{mm} \mathrm{Hg}$, and those who had terminated their anti- hypertensive medication without medical approval were classified as having untreated hypertension. Diabetes was recorded for patients taking oral hypoglycemic agents or insulin. Previous hemorrhagic (ICH and subarachnoid hemorrhage) and ischemic strokes (including transient ischemic attacks) were recorded. Cardiac disease history included previous myocardial infarction, coronary artery disease, heart failure, and atrial fibrillation. Recent heavy drinking was defined as weekly ingestion of at least 300 $\mathrm{g}$ of ethanol in the month preceding the stroke. These data were obtained from interviews with patients and/ or their relatives. Alcohol intake data were missing in $9 \%$ of patients. The patients' survival during the first 3 months after the onset of ICH was checked from hospital records and death records obtained from the Causes of Death Register maintained by Statistics Finland. Autopsy records were also examined.

\section{Medical Treatment}

All patients received standardized medical treatment according to the institutional protocol for acute cerebrovascular diseases. Blood pressure and plasma glucose levels were monitored. The MABP was calculated by adding one-third of the pulse pressure (systolic minus diastolic) to the diastolic pressure. Patients with admission hyperglycemia (plasma glucose $>8 \mathrm{mmol} / \mathrm{L}$ or 144 $\mathrm{mg} / \mathrm{dl}$ ) were given short-acting insulin to reach a target level of $<8 \mathrm{mmol} / \mathrm{L}$. Likewise, patients with admission pressure $>180 / 100 \mathrm{~mm} \mathrm{Hg}$ (considered MABP > $127 \mathrm{~mm}$ $\mathrm{Hg}$ ), received intravenous antihypertensive drugs (usually labetalol hydrochloride) to reach a target MABP $<120$ $\mathrm{mm} \mathrm{Hg}$.

\section{Statistical Methods}

Data were analyzed with commercially available statistical software (SPSS for Windows, version 12.0.1, SPSS, Inc.). For univariate statistics, conventional statistical tests were used. Univariate association of continuous variables was tested with the Spearman rank correlation coefficients. For life table analysis and the Cox proportional hazards regression model, each patient underwent follow-up until death or for 3 months after ICH. Cumulative survival rates were estimated with the Kaplan-Meier product limit method, and the curves of the different groups were compared with the log-rank test. The Cox proportional hazards model with a forward stepwise regression procedure was used to determine the significance of several variables in predicting RRs with 95\% CIs for death. The following variables, known at the beginning of follow-up, were analyzed: age, sex, history of hypertension, previous ischemic stroke, previous hemorrhagic stroke, cardiac disease, diabetes, cancer, hematoma size, location of the hematoma, presence of IVH, warfarin treatment, regular aspirin use, GCS score at admission, current smoking and recent heavy drinking status, plasma glucose level at admission, and blood pressure at admission. The assumption of proportionality was checked. The test for significance was based on changes in $\log$ (partial) likelihood. A 2-tailed probability value < 0.05 was considered statistically significant. 


\section{Results}

The patients' baseline characteristics are shown in Table 1. Diabetes, cardiac disease, advanced age, and the use of either warfarin or aspirin were significantly more common among the patients who died within 3 months of ICH onset. In addition, there was a significant $(\mathrm{p}<0.001)$ association between hypertensive status and case fatality.

The clinical characteristics are summarized in Table 2 . The patients who died within 3 months had significantly lower GCS scores, larger hematomas, and higher plasma glucose levels and MABPs at admission than those who did not; they were also more likely to have an IVH. There was a significant association between hematoma location and death rate: patients with infratentorial bleeding and those with extension of the putaminal hematoma into the thalamus and/or subcortical white matter showed a higher case fatality rate. Admission glucose levels were higher in those who died within 2 days (mean $\pm \mathrm{SD}, 11.1 \pm 4.1 \mathrm{vs}$ $7.6 \pm 3.0 \mathrm{mmol} / \mathrm{L} ; \mathrm{p}<0.001)$ and 3 months $(9.5 \pm 3.8 \mathrm{vs}$ $7.4 \pm 2.9 \mathrm{mmol} / \mathrm{L} ; \mathrm{p}<0.001)$ than in those who survived. Likewise, admission MABPs were higher in those who died within 2 days (mean $\pm \mathrm{SD}, 137 \pm 22$ vs $125 \pm 21 \mathrm{~mm}$ $\mathrm{Hg} ; \mathrm{p}<0.001)$ and within 3 months $(132 \pm 21$ vs $124 \pm 21$ $\mathrm{mm} \mathrm{Hg} ; \mathrm{p}<0.01)$ than in those who survived. There was a significant correlation between admission MABP and plasma glucose values $\left(r_{s}=0.20, p<0.001\right)$ even after the exclusion of patients with diabetes $\left(\mathrm{r}_{\mathrm{s}}=0.17, \mathrm{p}<0.01\right)$.

The predictors of death in the first 2 days and within 3 months after ICH identified with stepwise Cox regression after adjustment for sex are shown in Tables 3 and 4. Forty patients (11\%) died within 2 days, and 106 died (28\%) within 3 months. The significant independent predictors for death within 2 days were hematoma size, low GCS score, and preceding use of warfarin. The predictors for death within 3 months additionally included cardiac disease, IVH, advanced age, and high MABP on admission. A high admission plasma glucose level was not a significant predictor of death either within 2 days or within 3 months. In a separate analysis we replaced plasma glucose and MABP with diabetes and hypertension (grouping treated and untreated individuals together). Diabetes but not hypertension proved to be a significant independent predictor of death within 3 months of ICH (RR 1.61, 95\% CI 1.03-2.53; $\mathrm{p}<0.05$ ).

Next we analyzed the survival of patients with the highest (75th) quartile of admission MABP (MABP $>139 \mathrm{~mm} \mathrm{Hg}, 104$ patients) and plasma glucose (> 8.8 $\mathrm{mmol} / \mathrm{L}, 93$ patients). The 3-month survival rates of these patients were significantly lower than those of the patients with lower MABP and glucose at admission ( $\mathrm{p}<0.01$ ). Twenty-one (20.2\%) of 104, and 25 (26.9\%) of 93 patients belonging to the highest quartile according to admission MABP and plasma glucose level, respectively, died within 2 days. These patients had substantially larger hematomas compared with the others $(\mathrm{p}<0.001)$. We separately analyzed the 3-month survival of the patients who survived for 2 days or longer. Patients with high admission plasma glucose levels showed significantly $(\mathrm{p}<0.01)$ shorter survival within 3 months (Fig. 1) than the others. Patients with diabetes had a shorter 3-month survival period than
TABLE 1: Baseline characteristics stratified by outcome in 379 patients with spontaneous $\mathrm{ICH}^{*}$

\begin{tabular}{|c|c|c|c|}
\hline Characteristic & $\begin{array}{c}\text { Died W/in } \\
3 \text { Mos (106 } \\
\text { patients) }\end{array}$ & $\begin{array}{c}\text { Survived for } \\
3 \text { Mos (273 } \\
\text { patients) }\end{array}$ & All Patients \\
\hline male sex (\%) & $61(58)$ & $148(54)$ & $209(55)$ \\
\hline mean age $(y r s) \pm S D$ & $75 \pm 9.7$ & $67 \pm 12.0$ & $69 \pm 11.9$ \\
\hline $\begin{array}{l}\text { mean BMI }\left(\mathrm{kg} / \mathrm{m}^{2}\right) \pm \mathrm{SD} \\
\text { previous disease }(\%)\end{array}$ & $26.6 \pm 5.0$ & $27.2 \pm 5.2$ & $27.1 \pm 5.2$ \\
\hline $\begin{array}{l}\text { diabetes } \\
\text { hypertension }\end{array}$ & $33(31)$ & $35(13)$ & $68(18)$ \\
\hline no & $32(30)$ & $74(27)$ & $106(28)$ \\
\hline treated & $70(66)$ & $127(47)$ & $197(52)$ \\
\hline untreated & $4(4)$ & $72(26)$ & $76(20)$ \\
\hline ischemic stroke & $28(26)$ & $49(18)$ & $77(20)$ \\
\hline cancer & $14(13)$ & $26(10)$ & $40(11)$ \\
\hline cardiac disease $\dagger$ & $68(64)$ & $79(29)$ & $145(38)$ \\
\hline Gl bleeding & $4(4)$ & $8(3)$ & $12(3)$ \\
\hline current heavy drinker (\%)末 & $7 / 101(7)$ & 28/261 (11) & $35 / 362(10)$ \\
\hline $\begin{array}{l}\text { current smoker }(\%) \neq \\
\text { took anticoag medication (\%) }\end{array}$ & $9 / 102(9)$ & $25 / 256(10)$ & $34 / 359(9)$ \\
\hline no & $41(39)$ & $183(67)$ & $224(59)$ \\
\hline aspirin & $41(39)$ & $67(25)$ & $108(28)$ \\
\hline warfarin & $24(23)$ & $23(8)$ & 47 (12) \\
\hline
\end{tabular}

* For age, cardiac disease status, diabetes, and warfarin/aspirin history, $\mathrm{p}<0.001$. Abbreviations: anticoag = anticoagulation; $\mathrm{BMI}=$ body mass index; $\mathrm{Gl}$ = gastrointestinal.

+ Includes previous myocardial infarction, coronary artery disease, heart failure, and atrial fibrillation.

\$ Data not available in all patients.

nondiabetics $(\mathrm{p}<0.001)$. In contrast, we did not observe a significant difference in survival between those with or without high MABP at admission $(\mathrm{p}=0.35)$ (Fig. 2).

Medication was given to 184 patients to lower the high blood pressure noted at admission. This treatment was started immediately after admission. The patients who received medical treatment had significantly higher mean MABPs $(\mathrm{p}<0.001)$ than those who did not (mean $\pm \mathrm{SD}, 135 \pm 19$ vs $118 \pm 19 \mathrm{~mm} \mathrm{Hg}$ ). However, we did not observe any significant difference in either the 2-day or the 3-month survival rates between the treated and untreated patients. Nor did the treated patients differ from the untreated ones in initial hematoma volume $(25.8 \pm$ 34.2 vs $24.5 \pm 31.9 \mathrm{ml}$ ). Hematoma size did not show an association with admission MABP either in the whole population or among those who with a history of treated hypertension.

Hematoma volume was associated with admission plasma glucose level. After all patients with diabetes were excluded, the plasma glucose level increased with hematoma volume $\left(r_{s}=0.195, p<0.001\right)$. Seventy-three nondiabetic patients had admission hyperglycemia (blood glucose $>8 \mathrm{mmol} / \mathrm{L}$ ). They showed significantly shorter survival despite treatment with short-acting insulin than 
TABLE 2: Clinical characteristics stratified by outcome in 379 patients with spontaneous ICH*

\begin{tabular}{|c|c|c|c|c|}
\hline Characteristic & $\begin{array}{c}\text { Died W/in } 3 \text { Mos (106 } \\
\text { patients) }\end{array}$ & $\begin{array}{l}\text { Survived for } 3 \text { Mos ( } 273 \\
\text { patients) }\end{array}$ & All Patients & $p$ Value \\
\hline $\begin{array}{l}\text { med GCS score on admission (25th \& 75th } \\
\text { percentiles) }\end{array}$ & $10(5 \& 14)$ & $15(14 \& 15)$ & $14(12 \& 15)$ & $<0.001$ \\
\hline med vol ICH (25th \& 75th percentiles) & $30(10 \& 66)$ & $11(5 \& 21)$ & $12(6 \& 30)$ & $<0.001$ \\
\hline admission PGL >8.0 (\%) & $59(56)$ & $69(25)$ & $128(34)$ & $<0.001$ \\
\hline mean admission $\mathrm{PGL} \pm \mathrm{SD}$ & $9.5 \pm 3.8$ & $7.4 \pm 2.9$ & $8.0 \pm 3.3$ & $<0.001$ \\
\hline med admission PGL (25th \& 75th quartiles) & $8.4(6.5 \& 11.1)$ & $6.6(5.8 \& 8.2)$ & $6.9(6.0 \& 8.8)$ & $<0.001$ \\
\hline admission $\mathrm{BP}>180 / 100(\%)$ & $62(58)$ & $128(47)$ & $190(50)$ & $<0.05$ \\
\hline mean admission $\mathrm{MABP} \pm \mathrm{SD}$ & $131 \pm 21$ & $124 \pm 21$ & $126 \pm 21$ & $<0.001$ \\
\hline med admission MABP (25th \& 75th quartiles) & $132(118 \& 147)$ & $124(110 \& 138)$ & $127(110 \& 140)$ & $<0.01$ \\
\hline $\mathrm{IVH}(\%)$ & $74(70)$ & $70(26)$ & $144(38)$ & $<0.001$ \\
\hline hematoma location (\%) & & & & $<0.05$ \\
\hline subcortex & $15(14)$ & $81(30)$ & $96(25)$ & \\
\hline basal ganglia (combined) $\dagger$ & $54(51)$ & $111(41)$ & $165(44)$ & \\
\hline thalamus & $16(15)$ & $41(15)$ & $57(15)$ & \\
\hline cerebellum \& pons & $21(20)$ & $40(15)$ & $61(16)$ & \\
\hline
\end{tabular}

those with lower admission plasma glucose ( $\mathrm{p}<0.001)$. After patients with diabetes and those who died within the first 2 days were excluded, patients with hyperglycemia at admission still showed a higher 3-month death rate than those without $(\mathrm{p}<0.01)$. Among patients with hyperglycemia, those who survived had smaller hematomas than those who died $(13.6 \pm 12.2$ vs $47.2 \pm 44.8 \mathrm{ml}$; $\mathrm{p}<$ 0.001).

\section{Discussion}

We found high admission MABP to be an independent predictor of early death without any significant association with admission hematoma volume. On the other hand, a high admission plasma glucose level did not independently predict early death but was significantly associated with the severity of ICH (the larger the hematoma volume, the higher the plasma glucose level at admission). However, previously diagnosed diabetes predicted early death, whereas hypertension did not.

Our finding that admission hyperglycemia is not an independent predictor of early death either in patients with or without diabetes agrees with the conclusion of Capes and colleagues 5 in their meta-analysis of 4 previous studies. Hematoma volume was the main determinant of poor outcome, and admission hyperglycemia associated with the severity of bleeding. In many patients, a high plasma glucose level at admission was probably attributable to a stress reaction caused by the large hematoma. Stress-induced hyperglycemia has previously been shown to predict poor outcome after ischemic stroke and subarachnoid hemorrhage. ${ }^{5,11,15}$ Subarachnoid hemorrhage has been shown to result in massive sympathetic nervous ac- tivation, which could explain the high admission MABP and glucose levels. ${ }^{19}$ Acute ICH may also involve activation of the sympathetic nervous system reflecting a stress reaction. Accordingly, the same mechanism may lay behind high admission MABP and glucose among patients with ICH.

In our patient population, a high admission MABP predicted early death, but it was not significantly associated with hematoma volume. It has been reported that elevated blood pressure increases the risk of hematoma growth, ${ }^{17,20}$ and that hematoma growth is an independent risk factor for early death. ${ }^{8,12}$ We did not have systematic hematoma growth data, which could have been used to test whether a high admission MABP actually increased the hematoma growth rate. Furthermore, for moribund patients who died soon after admission, it was not possible to obtain follow-up CT scans. Previous investigations have shown that high blood pressure in the first 48 hours ${ }^{4,18,25,29}$ and rapid decline in MABP within 24 hours after presentation ${ }^{22}$ predict poor outcome and early death after ICH. However, it has not been demonstrated that acute lowering of blood pressure will result in a better outcome in patients who already have large hematomas at admission.

In our study, 40 patients died in the first 2 days, and 21 of these had had a high MABP at admission. Most of these patients (30/40) had large hematomas at admission, and we believe that some had high MABP due to reflex systemic hypertension resulting from elevated ICP (Cushing reflex). ${ }^{6}$ In patients with Cushing reflex, blood pressure is elevated concomitantly with ICP to maintain sufficient perfusion pressure in the brain. If ICP continues to increase, however, the vasomotor center fails, blood pres- 
Diabetes, hypertension, and outcome in patients with ICH

TABLE 3: Predictors of death within 2 days of $\mathrm{ICH}^{*}$

\begin{tabular}{lll}
\hline \multicolumn{1}{c}{ Variable } & \multicolumn{1}{c}{$\begin{array}{c}\text { Univariate RR } \\
(95 \% \mathrm{Cl})\end{array}$} & $\begin{array}{c}\text { Multivariate RR } \\
(95 \% \mathrm{Cl})\end{array}$ \\
\hline admission PGL (mmol/L) & $1.17(1.11-1.24) \S$ & $1.04(0.95-1.13)$ \\
mean RR (per mm Hg) & $1.02(1.01-1.04) \ddagger$ & $1.02(1.00-1.03)$ \\
ICH size (per $10 \mathrm{ml})$ & $1.24(1.18-1.30) \S$ & $1.12(1.03-1.22) \ddagger$ \\
presence of IVH & $5.98(2.85-12.56) \S$ & $1.32(0.53-3.27)$ \\
age (per year) & $1.05(1.02-1.08) \ddagger$ & $1.03(1.00-1.07)$ \\
GCS score on admission & $0.76(0.71-0.81) \S$ & $0.84(0.77-0.92) \S$ \\
basal ganglia \& combined & $3.58(1.24-10.33) \dagger$ & $1.02(0.32-3.30)$ \\
thalamus & $1.25(0.28-5.58)$ & $1.38(0.29-6.63)$ \\
cerebellum \& pons & $3.68(1.13-11.95) \dagger$ & $2.81(0.78-10.11)$ \\
cardiac disease & $3.07(1.60-5.87) \ddagger$ & $1.14(0.51-2.53)$ \\
warfarin use & $5.02(2.67-9.45) \S$ & $3.92(1.79-8.58) \ddagger$ \\
\hline
\end{tabular}

* In the multivariate analysis, RRs were adjusted for sex and the variables listed in the table. The RRs of categorical variables represent comparisons of patients with no risk factor.

$\dagger p<0.05$.

$\neq p<0.01$.

$\S p<0.001$.

sure rapidly declines, and death results within a couple of hours. Therefore, some patients who were already moribund at admission may have presented with low blood pressures, and this could explain why high admission MABP was not associated with hematoma volume.

A history of hypertension did not predict poor outcome. In our study, patients with a history of hypertension included patients with both treated and untreated hypertension. Those with untreated hypertension were relatively young, did not have a history of cardiovascular attacks, and ICH was the first severe manifestation of their disease. This agrees well with previous findings. In fact, untreated hypertension has been shown to be highly prevalent in patients with $\mathrm{ICH}$ and is a significant risk factor for first hemorrhagic stroke. ${ }^{30}$ The fact that patients with untreated hypertension were included in the group of patients with hypertension in our study as well as in a previous study ${ }^{14}$ could explain why a history of hypertension was not found to be an independent predictor of death or impaired outcome.

It has been suggested that effective lowering of blood pressure immediately after the onset of ICH may improve outcome, ${ }^{7}$ possibly because persistently elevated blood pressure may predispose to hematoma expansion. However, this may not be true in patients who already have large hematomas and therefore very high ICPs. Lowering blood pressure in such patients could further increase ICP and decrease perfusion pressure, which could rapidly promote failure of the vasomotor center and lead to death. We do not know whether rapid lowering of blood pressure is associated with an increased death rate in patients with large hematomas. Patients with small hematomas may benefit from lowering of blood pressure, but this has not been proven in controlled trials. The American guidelines recommend lowering of blood pressure in patients when increased ICP is not suspected (Class IIb, level of
TABLE 4: Predictors of death within 3 months after ICH*

\begin{tabular}{lll}
\hline \multicolumn{1}{c}{ Variable } & \multicolumn{1}{c}{$\begin{array}{c}\text { Univariate RR } \\
(95 \% \mathrm{Cl})\end{array}$} & $\begin{array}{c}\text { Multivariate RR } \\
(95 \% \mathrm{Cl})\end{array}$ \\
\hline admission PGL (mmol/L) & $1.13(1.08-1.17) \S$ & $1.04(0.99-1.10)$ \\
mean RR (per mm Hg) & $1.015(1.01-1.02) \S$ & $1.01(1.00-1.02) \dagger$ \\
size of ICH (per 10 ml) & $1.24(1.19-1.23) \S$ & $1.09(1.04-1.15) \ddagger$ \\
presence of IVH & $4.95(3.26-7.50) \S$ & $2.28(1.44-3.63) \S$ \\
age (per yr) & $1.06(1.04-1.08) \S$ & $1.04(1.02-1.07) \S$ \\
GCS score on admission & $0.77(0.74-0.81) \S$ & $0.83(0.79-0.87) \S$ \\
basal ganglia \& combined & $0.40(0.21-0.78) \ddagger$ & $1.61(0.87-2.97)$ \\
thalamus & $0.97(0.58-1.60)$ & $1.61(0.77-3.38)$ \\
cerebellum \& pons & $0.76(0.40-1.46)$ & $1.94(0.96-3.94)$ \\
cardiac disease & $3.39(2.28-5.05) \S$ & $2.32(1.49-3.62) \S$ \\
warfarin use & $3.71(2.24-6.15) \S$ & $1.81(1.11-2.96) \dagger$ \\
\hline
\end{tabular}

* In multivariate analysis, RRs were adjusted for sex and the variables are listed in the table. The RRs of categorical variables represent comparisons to patients with no risk factor.

$+p<0.05$.

$\neq p<0.01$.

$\S p<0.001$.

evidence C). ${ }^{3}$ A low rate of neurological deterioration and hematoma expansion has been reported in patients who undergo aggressive treatment for acute hypertension, ${ }^{23}$ yet the 1-month death rate was higher (30\%) in those who received treatment compared with those who did not (13\%). Accordingly, controlled studies are needed to demonstrate the benefit of aggressive treatment of admission hypertension. We did not observe any significant difference in case fatality rate between those who did or did not receive medical treatment for high admission MABP.

We were able show that diabetes is a predictor of early death after $\mathrm{ICH}$, as has already been suggested by the authors of 2 previous studies. ${ }^{1,21}$ Exactly how diabetes increases the risk of an early death remains unclear. Most of its effect on survival is explained by the severity of bleeding. Although diabetes was found to be a strong predictor of early death in both univariate and multivariate analysis, it was a much stronger predictor in univariate analysis. Animal experiments have shown that hyperglycemia causes brain edema and perihematomal cell death after $\mathrm{ICH},{ }^{26}$ and patients with diabetes may also have a higher incidence of infectious and cardiac complications. Unfortunately, because autopsies were not performed in all cases, we were unable to prove the role of such complications in our series. Finally, hyperglycemia correction did not result in better survival of our patients. However, the use of insulin treatment seems reasonable because it could prevent infectious complications, as has been shown to be the case in patients with diabetes after coronary surgery. ${ }^{13}$

The strict inclusion criteria and the relatively large and homogeneous patient population are strengths of the present study. We also tried to consider as many of the well-known potential risk factors for early death as possible and adjust for them in our analyses. We did not exclude patients based on hematoma location, and we 
S. Tetri et al.

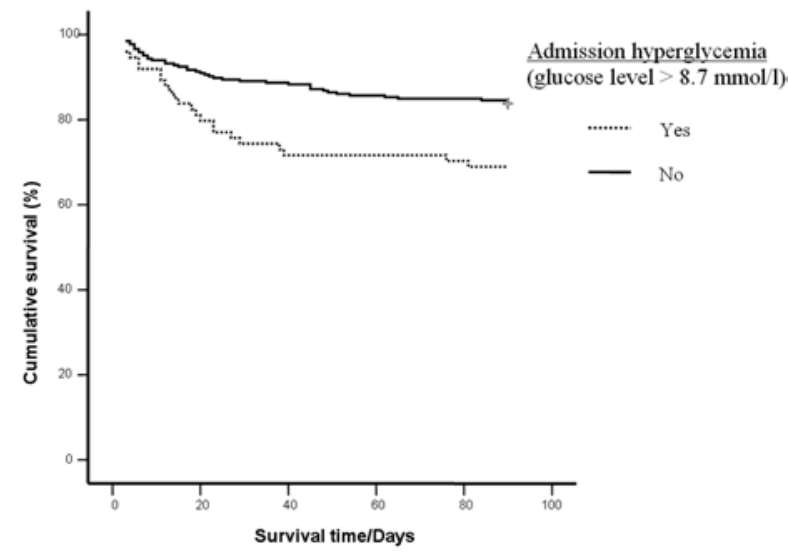

FIG. 1. Graph of mortality rate of patients who survived for at least 2 days after $\mathrm{ICH}$ according to the presence of hyperglycemia at admission (defined as 75th quartile, glucose $>8.7 \mathrm{mmol} / \mathrm{L}$ ). Dotted line indicates patients with hyperglycemia, and solid line indicates those without at admission. There was a significant difference between survival curves ( $p<0.01$, log-rank test).

tested glucose level and blood pressure simultaneously in a multivariate model. However, we did not control for fever, which has also been suggested as a predictor of early death, ${ }^{25}$ and we could not systematically investigate the hematoma growth rate. The patients who died before they could be transported to the hospital and those lacking admission plasma glucose values and blood pressure recordings were also excluded, as were those who were admitted to the Department of Neurosurgery for immediate operation. We do not believe that excluding patients who lacked relevant admission data caused any bias because the overall mortality rate of all the 453 patients with ICH was $28.4 \%$ compared with $28.0 \%$ in the 379 included patients. Patients with large cerebellar and subcortical hematomas who presented with an altered level of consciousness usually underwent surgical treatment. ${ }^{27}$ We excluded patients who needed immediate surgery because these patients usually receive postoperative care in intensive care units, where they are prone to the influence of many confounding factors such as ICP monitoring and treatment, sedation, use of mannitol, and infections. Such confounding factors could influence outcome and survival. By excluding surgical cases, we can better assess the natural outcome after conservatively treated $\mathrm{ICH}$.

\section{Conclusions}

In conclusion, in our cohort of patients who did not undergo surgery, we found that high blood pressure at admission was an independent risk factor for early death, whereas admission hyperglycemia was not. The latter clearly correlated with several factors reflecting the severity of the hemorrhage. Diabetes but not hypertension predicted early death. Controlled trials are needed to demonstrate whether lowering of high blood pressure and glucose levels during the acute phase after ICH results in a better outcome.

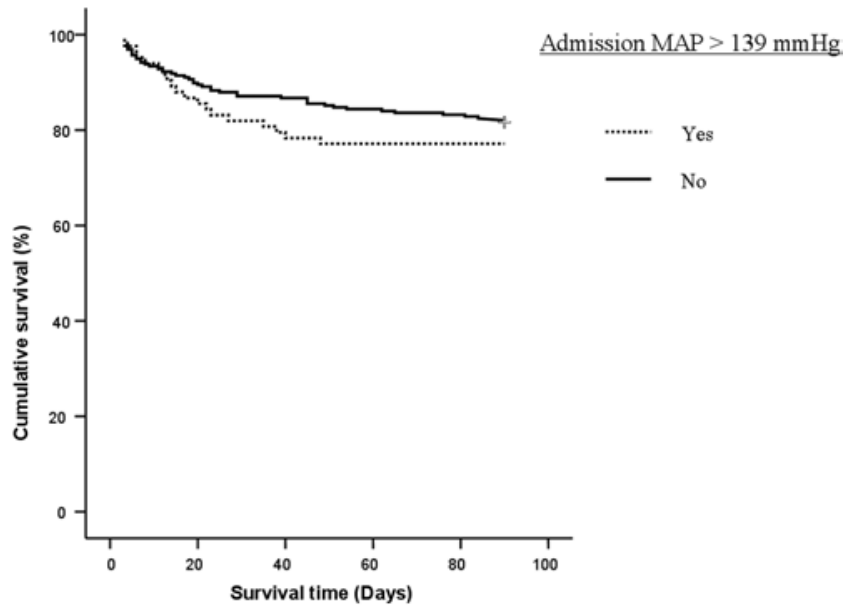

FIG. 2. Graph of mortality rate of patients who survived for at least 2 days after $\mathrm{ICH}$ according to the presence of hypertension at admission (defined as 75th quartile, MABP > $139 \mathrm{~mm} \mathrm{Hg}$ ). Dotted line indicates patients with hypertension, and solid line indicates those without at admission. There was no significant difference between survival curves $(p=0.35$, log-rank test $)$.

\section{Disclosure}

This study was supported in part by a grant to Dr. Tetri from the Orion Corporation.

\section{References}

1. Arboix A, Massons J, Garcia-Eroles L, Oliveres M, Targa C: Diabetes is an independent risk factor for in-hospital mortality from acute spontaneous intracerebral hemorrhage. Diabetes Care 23:1527-1532, 2000

2. Broderick JP, Brott TG, Duldner JE, Tomsick T, Huster G: Volume of intracerebral hemorrhage. A powerful and easy-touse predictor of 30-day mortality. Stroke 24:987-993, 1993

3. Broderick J, Connolly S, Feldmann E, Hanley D, Kase C, Krieger D, et al: Guidelines for the management of spontaneous intracerebral hemorrhage in adults: 2007 update: a Guideline from the American Heart Association/American Stroke Association Stroke Council, High Blood Pressure Research Council, and the Quality of Care and Outcomes in Research Interdisciplinary Working Group. Stroke 38:2001-2023, 2007

4. Brott T, Broderick J, Kothari R, Barsan W, Tomsick T, Sauerbeck L, et al: Early hemorrhage growth in patients with intracerebral hemorrhage. Stroke 28:1-5, 1997

5. Capes SE, Hunt D, Malmberg K, Pathak P, Gerstein H: Stress hyperglycemia and prognosis of stroke in nondiabetic and diabetic patients. A systematic review. Stroke 32:2426-2432, 2001

6. Cushing H: The blood-pressure reaction of acute cerebral compression illustrated by cases of intracranial hemorrhage: a sequel to Mutter lecture for 1901. Am J Med Sci 125:10171045,1903

7. Dandapani BK, Suzuki S, Kelley RE, Reyes-Inglesias Y, Duncan RC: Relation between blood pressure and outcome in intracerebral hemorrhage. Stroke 26:21-24, 1995

8. Davis SM, Broderick J, Hennerici M, Brun NC, Diringer MN, Mayer SA, et al: Hematoma growth is a determinant of mortality and poor outcome after intracerebral hemorrhage. Neurology 66:1175-1181, 2006

9. Fogelholm R, Avikainen S, Murros K: Prognostic value and determinants of first-day mean arterial pressure in spontaneous supratentorial intracerebral hemorrhage. Stroke 28:13961400, 1997 


\section{Diabetes, hypertension, and outcome in patients with ICH}

10. Fogelholm R, Murros K, Rissanen A, Avikainen S: Admission blood glucose and short term survival in primary intracerebral hemorrhage: a population based study. J Neurol Neurosurg Psychiatry 76:349-353, 2005

11. Frontera JA, Fernandez A, Claassen J, Schmidt M, Schumacher HC, Wartenberg K, et al: Hyperglycemia after SAH. Stroke 37:199-203, 2006

12. Fujii Y, Takeuchi S, Sasaki O, Minakawa T, Tanaka R: Multivariate analysis of predictors of hematoma enlargement in spontaneous intracerebral hemorrhage. Stroke 29:1160-1166, 1998

13. Hruska LA, Smith JM, Hendy MP, Fritz VL, McAdams S: Continuous insulin infusion reduces infectious complications in diabetics following coronary surgery. J Card Surg 20:403-407, 2005

14. Juvela S: Risk factors for impaired outcome after spontaneous intracerebral hemorrhage. Arch Neurol 52:1193-1200, 1995

15. Juvela S, Siironen J, Kuhmonen J: Hyperglycemia, excess weight, and history of hypertension as risk factors for poor outcome and cerebral infarction after aneurysmal subarachnoid hemorrhage. J Neurosurg 102:998-1003, 2005

16. Kaste M, Kwiecinski H, Steiner T, Mendelow D, Juvela S, Marchel A, et al: Recommendations for the management of intracranial haemorrhage-part 1: spontaneous intracerebral haemorrhage. Cerebrovasc Dis 22:294-316, 2006

17. Kazui S, Minematsu K, Yamamoto H, Sawada T, Yamaguchi T: Predisposing factors to enlargement of spontaneous intracerebral hematoma. Stroke 28:2370-2375, 1997

18. Leira R, Dávalos A, Silva Y, Gil-Peralta A, Tejada J, Garcia M, et al: Early neurologic deterioration in intracerebral hemorrhage: predictors and associated factors. Neurology 63:461467,2004

19. Naredi S, Lambert G, Eden E, Zall S, Runnerstam M, Rydenhag B, et al: Increased sympathetic nervous activity in patients with nontraumatic subarachnoid hemorrhage. Stroke 31:901906, 2000

20. Ohwaki K, Yano E, Nagashima H, Hirata M, Nagatomi T, Tamura A: Blood pressure management in acute intracerebral hemorrhage: relationship between elevated blood pressure and hematoma enlargement. Stroke 35:1364-1367, 2004

21. Passero S, Ciacci G, Ulivelli M: The influence of diabetes and hyperglycemia on clinical course after intracerebral hemorrhage. Neurology 61:1351-1356, 2003

22. Qureshi AI, Bliwise D, Bliwise N, Akbar M, Uzen G, Fran- kel M: Rate of 24-hours blood pressure decline and mortality after spontaneous intracerebral hemorrhage: a retrospective analysis with random effects regression model. Crit Care Med 27:480-485, 1999

23. Qureshi AI, Mohammad Y, Yahia A, Suarez J, Siddigui A, Kirmani J, et al: A prospective multicenter study to evaluate the feasibility and safety of aggressive antihypertensive treatment in patients with acute intracerebral hemorrhage. J Intensive Care Med 20:34-42, 2005

24. Qureshi AI, Tuhrim S, Broderick JP, Batjer HH, Hondo H, Hanley DF: Spontaneous intracerebral hemorrhage. N Engl J Med 344:1450-1460, 2001

25. Schwarz S, Häfner K, Aschoff A, Schwab S: Incidence and prognostic significance of fever following intracerebral hemorrhage. Neurology 54:352-361, 2000

26. Song EC, Chu K, Jeong SW, Jung KH, Kim SH, Kim M, et al: Hyperglycemia exacerbates brain edema and perihematomal cell death after intracerebral hemorrhage. Stroke 34:2215 2220, 2003

27. Tetri S, Mäntymäki L, Juvela S, Saloheimo P, Pyhtinen J, Rusanen $\mathrm{H}$, et al: Impact of ischemic heart disease and atrial fibrillation on survival after spontaneous intracerebral hemorrhage. J Neurosurg 108:1172-1177, 2008

28. Whitworth JA, World Health Organization, International Society of Hypertension Writing Group: 2003 World Health Organization (WHO)/Internatonal Society of Hypertension (ISH) statement on management of hypertension. J Hypertens 21:1983-1992, 2003

29. Willmot M, Leonardi-Bee J, Bath PMW: High blood pressure in acute stroke and subsequent outcome. A systematic review. Hypertension 43:18-24, 2004

30. Woo D, Haverbusch M, Sekar P, Kissela B, Khoury J, Schneider A, et al: Effect of untreated hypertension on hemorrhagic stroke. Stroke 35:1703-1708, 2004

Manuscript submitted May 7, 2008

Accepted August 8, 2008.

Please include this information when citing this paper: published online December 1, 2008; DOI: 10.3171/2008.8.JNS08445.

Address correspondence to: Sami Tetri, M.D., Department of Neurosurgery, Oulu University Hospital, FIN-90029, Oulu, Finland. email: sami.tetri@ppshp.fi. 